\title{
An Optimized Model for the Local Compression Deformation of Soft Tissue
}

\author{
Xiaorui Zhang ${ }^{1,2,}$, Xuefeng $\mathrm{Yu}^{1}$, Wei Sun ${ }^{2}$ and Aiguo Song ${ }^{3}$ \\ ${ }^{1}$ Jiangsu Engineering Center of Network Monitoring, Engineering Research Center of Digital Forensics, Ministry \\ of Education, School of Computer and Software, Nanjing University of Information Science \& Technology, \\ Nanjing 210044, China \\ [e-mail: zxr365@126.com] \\ ${ }^{2}$ Jiangsu Collaborative Innovation Center of Atmospheric Environment and Equipment Technology (CICAEET), \\ Nanjing University of Information Science \& Technology, Nanjing 210044, China \\ [e-mail: sunw0125@163.com] \\ ${ }^{3}$ State Key Laboratory of Bioelectronics, Jiangsu Key Lab of Remote Measurement and Control, School of \\ Instrument Science and Engineering, Southeast University, Nanjing 210096, China \\ [e-mail: a.g.song@seu.edu.cn] \\ *Corresponding author: Xiaorui Zhang
}

Received Decebmer 19, 2019; revised January 15, 2020; accepted February 8, 2020; published February 29, 2020

\begin{abstract}
Due to the long training time and high training cost of traditional surgical training methods, the emerging virtual surgical training method has gradually replaced it as the mainstream. However, the virtual surgical system suffers from poor authenticity and high computational cost problems. For overcoming the deficiency of these problems, we propose an optimized model for the local compression deformation of soft tissue. This model uses a simulated annealing algorithm to optimize the parameters of the soft tissue model to improve the authenticity of the simulation. Meanwhile, although the soft tissue deformation is divided into local deformation region and non-deformation region, our proposed model only needs to calculate and update the deformation region, which can improve the simulation real-time performance. Besides, we define a compensation strategy for the "superelastic" effect which often occurs with the mass-spring model. To verify the validity of the model, we carry out a compression simulation experiment of abdomen and human foot and compare it with other models. The experimental results indicate the proposed model is realistic and effective in soft tissue compression simulation, and it outperforms other models in accuracy and real-time performance.
\end{abstract}

Keywords: Mass-spring model, simulated annealing algorithm, virtual surgery, soft tissue deformation

This work was supported, in part, by the National Nature Science Foundation of China under grant numbers 61502240, 61502096, 61304205, 61773219; in part, by the Natural Science Foundation of Jiangsu Province under grant number BK20191401; in part, by the Priority Academic Program Development of Jiangsu Higher Education Institutions (PAPD) fund; in part, by the Collaborative Innovation Center of Atmospheric Environment and Equipment Technology (CICAEET) fund. 


\section{Introduction}

The important development trend in the current medical field is the integration of Chinese and Western medicine, it combines the concept of Chinese medicine treatment with modern medical technology to diagnose and treat various diseases more effectively [1-5]. Pressing is one of the indispensable operations in medical treatment. In the diagnosis and treatment of traditional Chinese medicine, the diagnosis of essential hypertension, coronary heart disease, gastroptosis and gastric ulcer can be diagnosed by pressing acupoints. Meanwhile, pressing acupoints also has a significant effect in treating dysmenorrhea, colds, allergic rhinitis and constipation. Modern medical treatment also uses pressing operations to diagnose and treat diseases. Early pregnancy and early appendicitis are diagnosed by pressing the abdomen. Cardiopulmonary resuscitation and arterial hemostasis also performed by pressing operation [6-7]. In addition, the position, strength, angle and frequency of pressing in the pressing operation affect the accuracy and effectiveness of the diagnosis and treatment. Therefore, it is necessary for the doctor to improve the pressing skill through a large number of exercises. However, the traditional training method spends a long time, and the training effect is not obvious in a short time.

With the wide application of virtual reality technology in surgical training, the above problems have been gradually solved. Based on the virtual reality-based soft tissue model, the interns repeatedly operate the soft tissue model through the force feedback device to achieve the training purpose, where the validity and authenticity of the model will directly reflect the quality of the training. Nowadays, the finite element model [8-10], the meshless model [11-12] and the mass-spring model [13-14] are commonly used in virtual surgery training. The finite element model has high precision and adaptability, it can simulate large-scale soft tissue deformation, but its modeling is relatively complex, and it requires a lot of complicated numerical calculations, not suitable for real-time performance [15-16]. Wei et al. [17] proposed a method for rendering the human head stiffness based on the finite element model. This model can effective to simulates the deformation realistically. However, it has high computational complexity and poor real-time performance in the stiffness rendering. Samei et al. [18] proposed a real-time deformation registration method based on the finite element for $3 \mathrm{D}$ to $2 \mathrm{D}$ transrectal ultrasound images, but the modeling process is complex and the computational efficiency needs to be further improved. Traa et al. [19] proposed an MRI-based 3D finite element model to simulate the tibialis anterior muscle of rats and perform indentation tests with high simulation accuracy. The meshless model is composed of nodes scattered in the spatial domain. It does not need to be mesh, and has good stability and high computational efficiency. However, it still has some problems with the authenticity of deformation [20]. An et al. [21] proposed a new photon propagation model with tightly supported radial basis functions and meshless methods to achieve fluorescence molecular tomography, which has higher accuracy, but there is still room for improvement in accuracy. Zhou et al. [22] proposed a radial-based meshless three-dimensional model based on the Marquardt algorithm and they simulated the real-time deformation of the liver by the proposed model. The proposed model has high performance for the real-time simulation, but it cannot fully display the biomechanical properties of soft tissues. The structure of the mass-spring model is simple and easy to implement, it also has high computational efficiency, but it is difficult to achieve high accuracy [23-25]. Tang et al. [26] proposed a virtual laparoscopic training system based on the Visible Chinese Human (VCH) model. Although this system 
achieves high computational efficiency by adopting improved mass-spring model and morph target animation to simulate soft tissue deformation, the precision is relatively low. Li et al. [27] proposed a surface mass-spring model with flexion springs based on volume structure, which improves the deformation accuracy and calculation efficiency. However, the model parameters are difficult to select and the authenticity also needs to be improved.

In order to improve the authenticity of soft tissue deformation simulation and reduce the computational cost, we propose an optimized model for the local compression deformation of soft tissue. This model uses the simulated annealing algorithm to optimize the parameters since that the algorithm has strong convergence, robustness and global optimization ability [28-31], divides the soft tissue deformation into local deformation region and non-deformation region. Meanwhile, the deformation calculation only involves the deformation region. In addition, this model also sets a compensation strategy to prevent the model from "superelastic" effect [32-33]. The main contributions of this paper are summarized as follows:

(1) We refer to the finite element model to make the model more realistically simulate the deformation of soft tissue. We use the simulated annealing algorithm to optimize the parameters for the optimal spring stiffness coefficient and the damping coefficient of the model.

(2) We adopt minimum vertical stress to calculate the vertical depth of the load center point under the initial contact surface. The vertical depth as the radius is used to divide the soft tissue into the local deformation region and non-deformation region. Since only the points in the local deformation region are calculated, the calculation cost can be effectively reduced.

(3) We set a compensation strategy for the over-compressed case to prevent the model from being "superelastic" due to excessive local pressure for ensuring the validity of the model.

The organization of this paper is as follows: Section 2 describes the construction of the soft tissue model, establishes the kinematics equation, optimizes the model parameters, and divides the deformation region and the non-deformation region, as well as sets a compensation strategy for the over-compressed case. Section 3 introduces the experimental environment, shows the soft tissue pressing process and rendering effects, and conducts the evaluation experiment. In the last section, we make a summary of our work.

\section{Method}

The mass-spring model divides the soft tissue into $n$ points, and the points are connected by a spring to form a mesh. To express the viscoelastic properties of soft tissues, a parallel connection between spring and damper is adopted in this paper. The mass-spring model is generally divided into two types: surface model and volume model. The surface model is fast, but it only reflects the surface deformation characteristics of soft tissue, and can not represent its volume information. The volume model can simultaneously represent the surface deformation characteristics and internal structure of soft tissue. The volume model generally includes two kinds of hexahedron and tetrahedron. The hexahedron has a simple structure but lacks stability. Under the same volume, the tetrahedron has $50 \%$ springs more than hexahedron and it also has a better stability. Therefore, this paper uses a mass-spring model based on the tetrahedral topology to construct virtual soft tissue.

\subsection{Mass-Spring Model}

The tetrahedral topology adopted in this paper is shown in Fig. 1. 


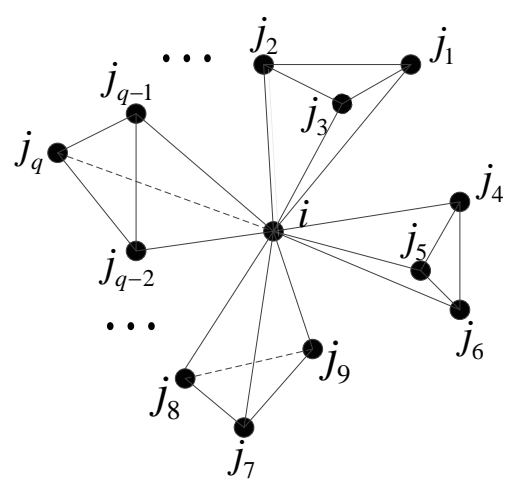

Fig. 1. Tetrahedral topology

We set the position of any point $i$ in the mass-spring model and any one of its neighboring point $j$ are $p_{i}$ and $p_{j}$, respectively. The spring stiffness coefficient and damping coefficient between the two mass points are $k_{i j}$ and $d_{i j}$, respectively. The initial length of the spring is represented by $l_{i j}^{0}$. Then the internal force $F_{i}^{\text {int }}$ of the point $i$ can be expressed as:

$$
F_{i}^{\mathrm{int}}=\sum_{\forall j \in S_{i}}\left(k_{i j}\left(\left|p_{j}-p_{i}\right|-l_{i j}^{0}\right)-d_{i j} \frac{\left(v_{j}-v_{i}\right)\left(p_{j}-p_{i}\right)}{\left|p_{j}-p_{i}\right|}\right) \frac{p_{j}-p_{i}}{\left|p_{j}-p_{i}\right|}
$$

where $S_{i}$ is the set of springs connected to point $i, v_{j}$ and $v_{i}$ represent the velocity of point $j$ and $i$, respectively.

In order to ensure volume conservation, the volume force is defined at each point. We set the center of gravity of the tetrahedron $w$ as $p_{w b}$, then the volume force $F_{i}^{v o l}$ of the point $i$ is:

$$
F_{i}^{v o l}=\sum_{\forall w \in \Omega_{i}}\left(V_{w}^{c u r}-V_{w}^{\text {init }}\right) \frac{p_{i}-p_{w b}}{\left|p_{i}-p_{w b}\right|}
$$

where $\Omega_{i}$ represents all tetrahedral collections containing point $i, V_{w}^{\text {cur }}$ and $V_{w}^{\text {init }}$ represent the current volume and initial volume of tetrahedral $w$, respectively.

The kinematic equation of point $i$ can be calculated as follows:

$$
m_{i} \frac{\mathrm{d}^{2} x_{i}}{\mathrm{~d} t^{2}}=F_{i}^{\mathrm{int}}+F_{i}^{\mathrm{vol}}+F_{i}^{e x t}
$$

where $m_{i}$ is the mass of the point $i$ and $F_{i}^{e x t}$ is the external force of the point $i$.

\subsection{Simulated Annealing Algorithm for Parameter Optimization}

In the soft tissue modeling of virtual surgery, setting the parameters of the mass-spring model is a diffficult problem. To improve the authenticity of soft tissue simulation, this paper refers to the finite element model and adopts the simulated annealing algorithm to optimize the spring stiffness coefficient and damping coefficient of the model. The steps are shown as follows: 
Step1: given the initial temperature $T_{n}$, the termination temperature $T_{f}$, the annealing coefficient $\lambda$, the number of internal cycles $L$, and randomly initialize a set of parameters $S=\left(k_{i j}, d_{i j}\right)$;

Step2: under temperature $T_{n}$, randomly generate a new set of parameters $S^{\prime}$ in the field of the currently better set of parameters $S$, calculate the objective function value increment $\Delta f=f\left(S^{\prime}\right)-f(S)$, if $\Delta f<0$ then let $S=S^{\prime}$, otherwise, according to the Metropolis criterion, accept $S$ as the currently optimal set of parameters $S$ with the probability of $\min \left\{1, \exp \left(-\Delta f / T_{n}\right)\right\}>$ random $[0,1]$, where the objective function is defined as Hausdorff distance function for image matching [34-37], which is expressed as follows:

$$
\begin{gathered}
f(S)=f\left(k_{i j}, d_{i j}\right)=H\left(N^{M S M}, N^{F E M}\right)=\max \left\{h\left(N^{M S M}, N^{F E M}\right), h\left(N^{F E M}, N^{M S M}\right)\right\} \\
h\left(N^{M S M}, N^{F E M}\right)=\max _{p_{m} \in N^{M S M}}\left\{\min _{p_{f} \in N^{F E M}}\left\{d\left(p_{m}, p_{f}\right)\right\}\right\} \\
h\left(N^{F E M}, N^{M S M}\right)=\max _{p_{f} \in N^{F E M}}\left\{\min _{p_{m} \in N^{M S M}}\left\{d\left(p_{m}, p_{f}\right)\right\}\right\}
\end{gathered}
$$

where $N^{M S M}, N^{\text {FEM }}, p_{m}, p_{f}$, and $d\left(p_{m}, p_{f}\right)$ represent the key point set of mass-spring model, the key point set of finite element model, the key point position of mass-spring model, the key point position of finite element model, and the absolute distance between point $p_{m}$ and point $p_{f}$, respectively.

Step3: determine whether the specified number of iterations is reached under temperature $T_{n}$. If the condition is met, go to Step4, otherwise return to Step2;

Step4: conduct cooling operation, let $n=n+1, T_{n+1}=\lambda T_{n}$;

Step5: determine whether the set termination temperature is reached. If the termination condition is met, output a set of optimal parameters $S=\left(k_{i j}, d_{i j}\right)$, otherwise return to Step2.

Soft tissue deformation can be simulated more realistically by using the optimal spring stiffness and damping coefficients which determined by the above simulated annealing algorithm.

\subsection{Local Deformation Calculation}

Soft tissue deformation usually occurs locally and has a little effect outside the local deformation. To reduce the computational overhead, we divide the soft tissue compression deformation into the local deformation region and non-deformation region. Meanwhile, the vertical stress component plays a major role in material failure [38], we only consider the role of vertical stress component in soft tissue compression. Assuming that an indenter acts on the soft tissue with uniform pressure, the vertical stress $F_{\perp}$ is expressed as:

$$
F_{\perp}=F_{c}\left[-1+\frac{h^{3}}{\left(r^{2}+h^{2}\right)^{3 / 2}}\right]
$$


where $F_{\perp}, F_{c}, h$ and $r$ represent the vertical stress, the contact pressure applied to the soft tissue, the vertical depth of the load center point below the contact surface, and the radius of the indenter, respectively. Fig. 2 shows the interaction diagram of the indenter and soft tissue under unidirectional external load. The contact pressure $F_{c}$ can be expressed as:

$$
F_{c}=\frac{1}{\pi}\left(\frac{6 F_{\text {uni }}^{\text {ext }}\left(\frac{E}{1-\mu^{2}}\right)^{2}}{r^{2}}\right)^{1 / 3}\left(1-\frac{r}{x_{z}}\right)^{1 / 2}
$$

where $F_{u n i}^{e x t}, E, \mu$ and $x_{z}$ represent unidirectional external load, Young's modulus, Poisson's ratio, and soft tissue deformation displacement under the action of unidirectional external load $F_{u n i}^{\text {ext }}$, respectively.

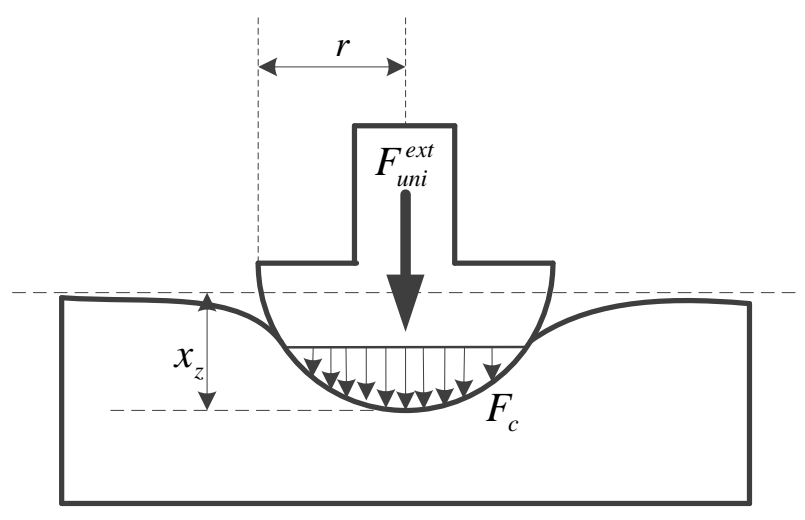

Fig. 2. Interaction diagram of indenter and soft tissue under unidirectional external load

As shown in Fig. 3, the vertical depth of the load center point corresponding to the minimum vertical stress component $F_{\perp \text { min }}$ under the initial contact surface is $h_{\max }$. We take the vertical depth $h_{\max }$ as the radius of the local deformation region. The inner region of the radius as the local deformation region, and the region outside the radius as the non-deformation region. The minimum vertical stress component $F_{\perp \min }$ can be calculated and determined through the experiment, and then the local deformation radius $h_{\max }$ can be calculated by equation (7) and (8). The local deformation range is determined by the external load and displacement of the contact point in each iteration dynamically, and the points of the non-deformation region will not be deformed. 


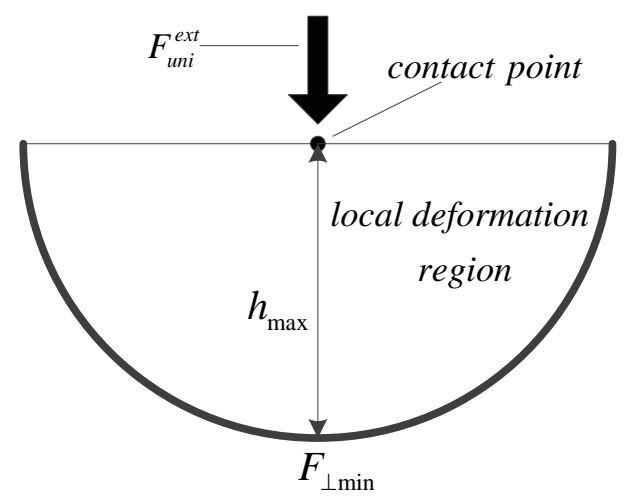

Fig. 3. Diagram of local deformation region diagram

Velocity-Verlet numerical integration method is fast for calculating and has high accuracy [39], so it can be used to solve kinematic equations:

$$
\begin{gathered}
x_{i}(t+\Delta t)=x_{i}(t)+v_{i}(t) \Delta t+\frac{F_{i}(t)}{2 m_{i}} \Delta t^{2} \\
v_{i}(t+\Delta t)=v_{i}(t)+\frac{F_{i}(t+\Delta t)+F_{i}(t)}{2 m_{i}} \Delta t
\end{gathered}
$$

where $x_{i}(t+\Delta t), x_{i}(t), v_{i}(t), \Delta t, F_{i}(t), v_{i}(t+\Delta t), v_{i}(t)$ and $F_{i}(t+\Delta t)$ represent the displacement of point $i$ at time $t+\Delta t$ and $t$, the velocity of point $i$ at time $t$, a time step, the resultant force on point $i$ at time $t$, the velocity of point $i$ at time $t+\Delta t$ and $t$, and the resultant force on point $i$ at time $t+\Delta t$, respectively.

\subsection{Over-Compressed Compensation}

When a large force is concentrated on the local soft tissue, the mass-spring model will fall into the problem of local deformation, which is called the "superelastic" effect. Therefore, a compensation strategy for the over-compressed situations need to be set. When the spring length is less than $\left(1-\tau_{c}\right) l_{i j}^{0}$, we move the spring back to $\left(1-\tau_{c}\right) l_{i j}^{0}$ by using over-compressed compensation. Over-compressed compensation is defined as follows:

$$
C_{\text {comp }}\left(p_{i}, p_{j}\right)=\left|p_{i}-p_{j}\right|-\left(1-\tau_{c}\right) l_{i j}^{0} \geq 0
$$

where $\tau_{c}$ represents the critical compression ratio. If the inequality (11) is not satisfied, we will correct the points as follows: $p_{i} \leftarrow p_{i}+\Delta p_{i}, p_{j} \leftarrow p_{j}+\Delta p_{j}$, the correction phase is defined as follows:

$$
\begin{gathered}
\Delta p_{i}=-\frac{1}{2} C_{\text {comp }}\left(p_{i}, p_{j}\right) \cdot \frac{p_{i}-p_{j}}{\left|p_{i}-p_{j}\right|} \\
\Delta p_{j}=\frac{1}{2} C_{\text {comp }}\left(p_{i}, p_{j}\right) \cdot \frac{p_{i}-p_{j}}{\left|p_{i}-p_{j}\right|}
\end{gathered}
$$




\section{Experiments and Results}

\subsection{Data Acquisition}

A three-dimensional tetrahedral mesh model is derived by processing soft tissue CT data with software Amira. The points are connected by springs to form a mesh and subdivided by tetrahedron.

\subsection{Experimental Environment}

In this paper, 3D Max, OpenGL, VC ++2017, etc. are used to establish the model. The PC equipped with Intel Core i9-7960x CPU, NVIDIA GeForce 1080Ti graphics card as well as Sensable Phantom Omni force tactile device, etc. are used to build the soft tissue interactive simulation system. The simulation environment is shown in Fig. 4.

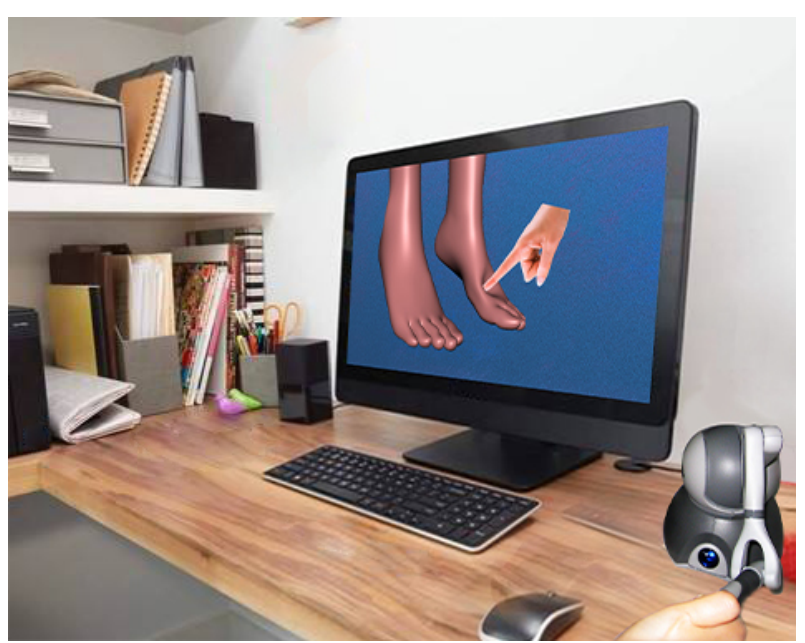

Fig. 4. The simulation environment

\subsection{Compression Simulation of Soft Tissue}

In the virtual surgery training, the quality of the soft tissue model affects the training effect directly. To verify the validity of the proposed model, we simulate the local press operation of the abdomen and human foot. As shown in Fig. 5 and Fig. 6, a virtual finger model is used to apply a pressing force of $0.8 \mathrm{~N}, 1.6 \mathrm{~N}$ and $2.4 \mathrm{~N}$ to the abdomen and human foot. According to observe the local compression deformation effect of the abdomen and human foot model, we can see that the deformation effect is realistic and meets the authenticity of human-computer interaction.

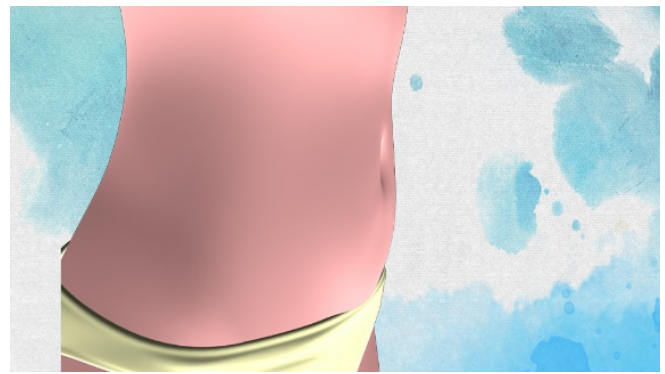

(a) before interaction

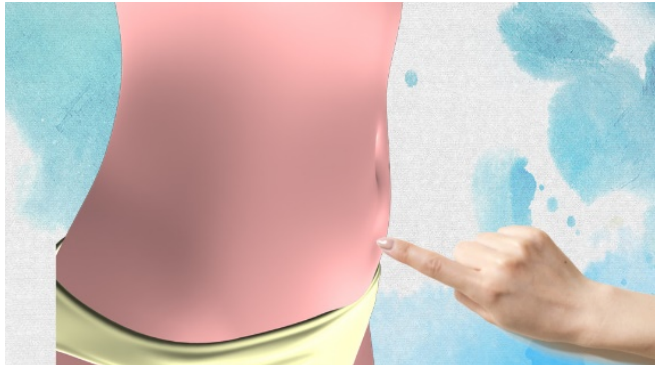

(b) $0.8 \mathrm{~N}$ 


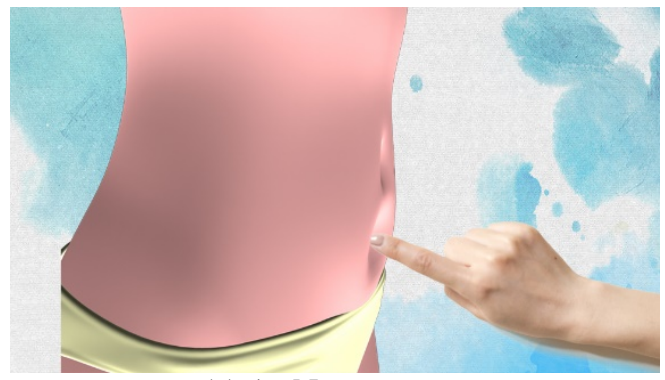

(c) $1.6 \mathrm{~N}$

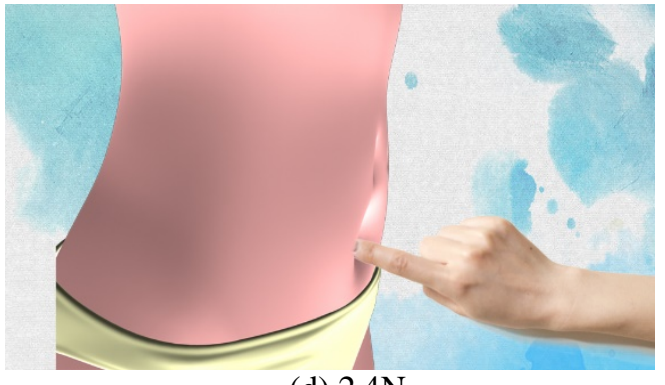

(d) $2.4 \mathrm{~N}$

Fig. 5. Local compression deformation effect of the abdomen

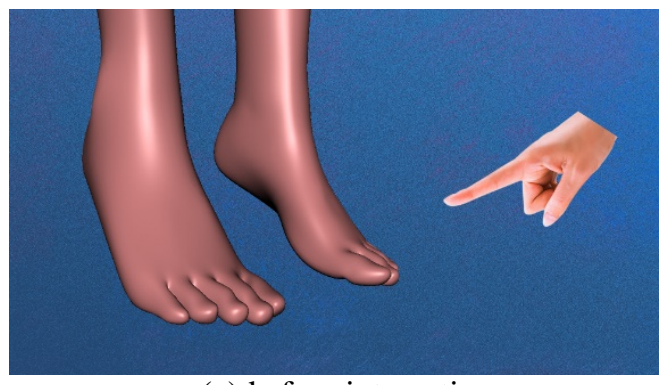

(a) before interaction

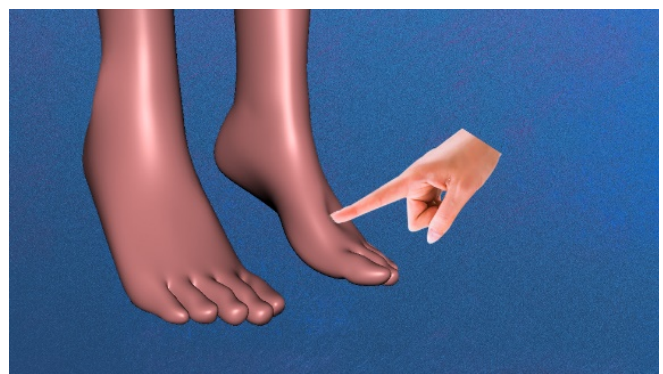

(c) $1.6 \mathrm{~N}$

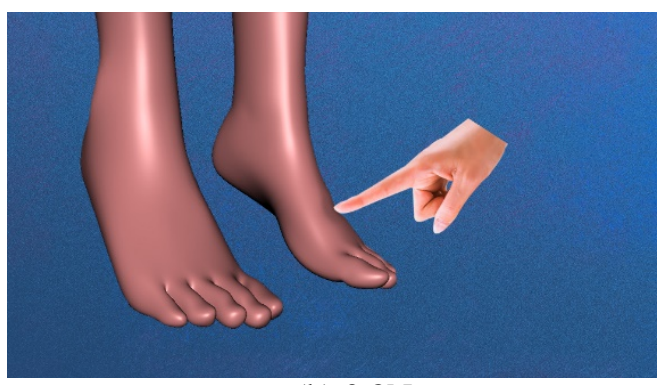

(b) $0.8 \mathrm{~N}$

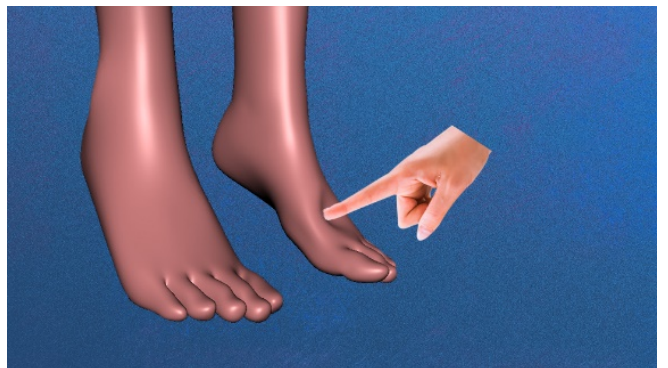

(d) $2.4 \mathrm{~N}$

Fig. 6. Local compression deformation effect of the human foot

\subsection{Accuracy Verification}

The parameters are very important for model quality. Therefore, we refer to the finite element model to simulate the soft tissue deformation behavior more accurately. We also adopt the simulated annealing algorithm to optimize the spring stiffness coefficient $k_{i j}$ and damping coefficient $d_{i j}$ of the mass-spring model. The parameters of simulated annealing algorithm in this paper are set as follows: the initial temperature $T_{n}=100(n=0)$, the termination temperature $T_{f}=0.001$, the annealing coefficient $\lambda=0.98$ and the number of internal cycles $L=200$. As shown in Fig. 7, during the optimization process, as the temperature changes, the dynamic curve of the two parameters jumps continuously in a trapezoidal shape, and finally converges to the optimal parameters. 


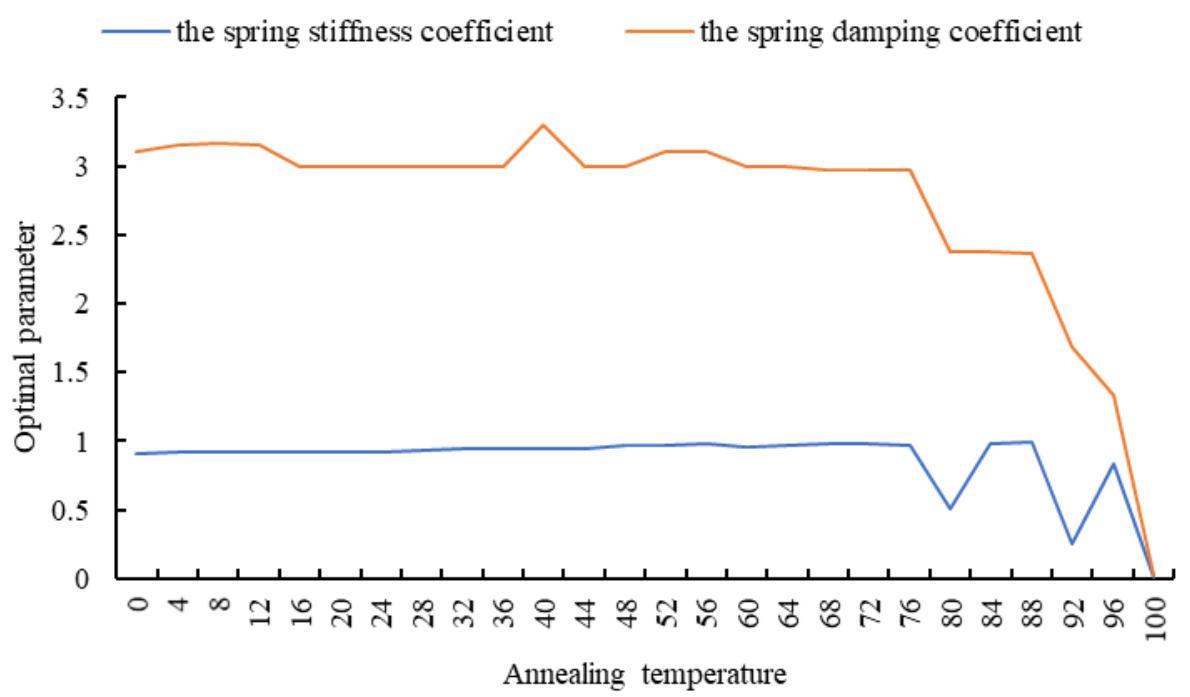

Fig. 7. Convergence trend of parameters with temperature $T_{n}$

We apply the optimal parameters $k_{i j}=0.91 \mathrm{~N} / \mathrm{mm}$ and $d_{i j}=3.11 \mathrm{Ns} / \mathrm{m}$ to the proposed model and compare the force-displacement curves of our proposed model to the MRI-based 3D finite element model [19]. As shown in Fig. 8, the force-displacement curve of our proposed model highly approximate to the MRI-based 3D finite element model. It indicates that our proposed model meets the accuracy requirements in virtual surgery training.

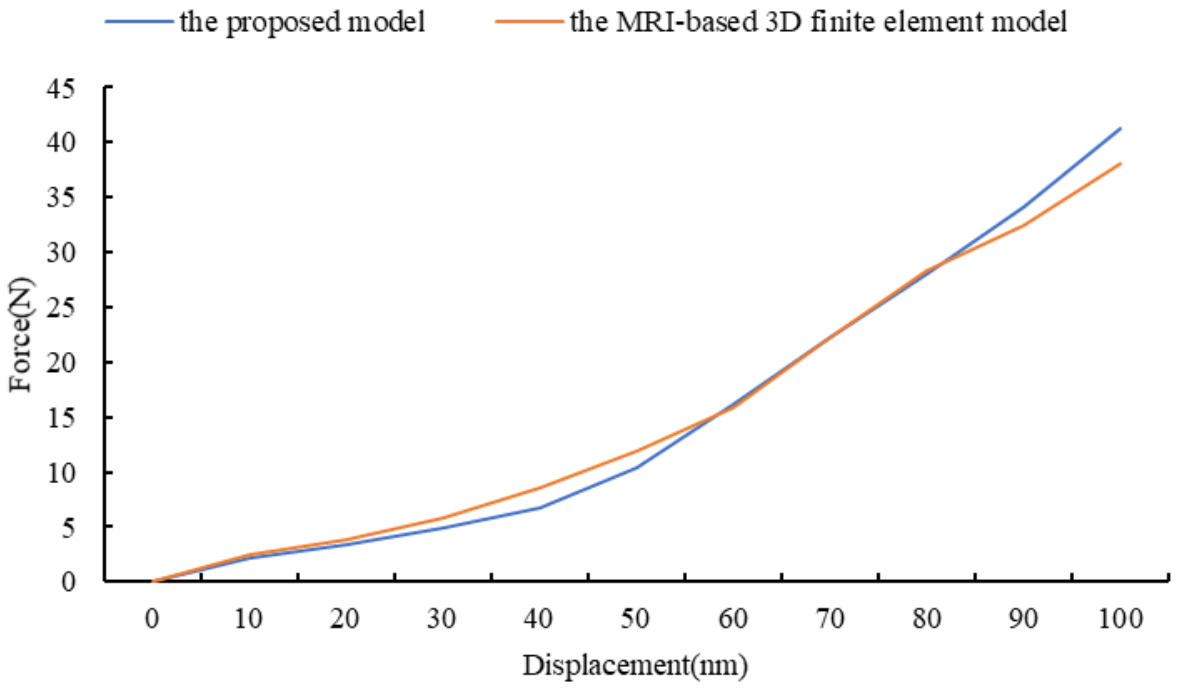

Fig. 8. Force-displacement curve of the proposed model and MRI-based three-dimensional finite element model

\subsection{Real-Time Verification}

The real-time performance of a model is an important indicator affecting virtual surgery training directly. To verify the real-time performance of our proposed model, we select 10 
groups of pressure in the range of $0-4 \mathrm{~N}$ and compare the time overhead from complete to deformation of our proposed model, the meshless model [40], the mass-spring model [41] and the finite element model [42] under the same experimental environment. As shown in Fig. 9, the time overhead of our proposed model is outperforms the rest of models in most case. It indicates that our proposed model suitable for real-time virtual surgery training.

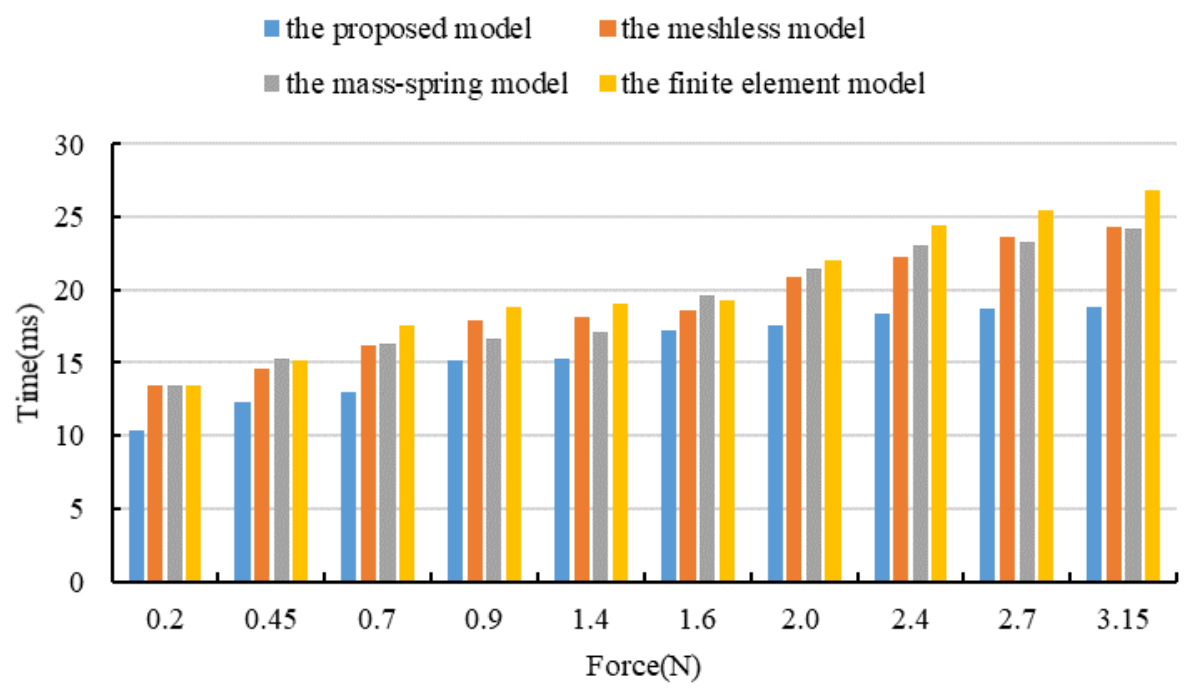

Fig. 9. Time overhead for model deformation

\subsection{Analysis of Experimental Training Effect}

We invite 1 chief physician, 1 associate chief physician, 1 attending physician and 20 interns from the First Affiliated Hospital of Nanjing Medical University to verify the effectiveness of our proposed model. We assign 3 physicians to number 1-3, and randomly divide 20 interns into two groups for abdominal press training. Two groups undergo actual abdominal compression training for 30 minutes before the assessment. Then the first group receive $30 \mathrm{~min}$ virtual abdominal press training through the virtual surgical system, and the second group perform 30min press training on the real abdomen. The two groups of interns perform abdominal press operation on three physicians before and after the training, respectively. The three physicians score comprehensively based on the intern's operational proficiency, accuracy and other indicators, with a perfect score of 10 points. The score weights of chief physicians, associate chief physicians and attending physicians are $45 \%, 35 \%$ and $20 \%$, respectively. Finally, we use the comprehensive index method to calculate and compare the comprehensive evaluation values of the two groups of interns [43-45]. Their comprehensive evaluation value $y_{i}$ is calculated as follows:

$$
y_{i}=\sum_{j=1}^{3} \frac{X_{i j}}{10} w_{j}(i=1,2,3, \ldots, 10)
$$

where $x_{i j}$ and $w_{j}$ represent the comprehensive score given by physician $j$ to intern $i$ and the score weight of physician $j$, respectively. As shown in Table 1, the comprehensive evaluation values of the two groups of interns before training are almost same. After the 
training, the comprehensive evaluation value of the first group of interns is generally higher than second group. The experimental results show that the interns perform better and are more proficient and accurate in the real abdominal press operation after repeated practice of virtual press operation.

Table 1. Comprehensive evaluation values of interns

\begin{tabular}{|c|c|c|c|c|}
\hline \multirow{2}{*}{ Interns } & \multicolumn{2}{|c|}{ Before training } & \multicolumn{2}{c|}{ After training } \\
\cline { 2 - 5 } & Group 1 & Group 2 & Group 1 & Group 2 \\
\hline 1 & 0.525 & 0.400 & 0.955 & 0.790 \\
\hline 2 & 0.500 & 0.460 & 0.945 & 0.795 \\
\hline 3 & 0.400 & 0.500 & 0.955 & 0.725 \\
\hline 4 & 0.375 & 0.320 & 0.900 & 0.820 \\
\hline 5 & 0.400 & 0.400 & 1.000 & 0.670 \\
\hline 6 & 0.600 & 0.545 & 0.955 & 0.840 \\
\hline 7 & 0.590 & 0.300 & 0.900 & 0.900 \\
\hline 8 & 0.510 & 0.400 & 1.000 & 0.710 \\
\hline 9 & 0.415 & 0.435 & 0.855 & 0.790 \\
\hline 10 & 0.500 & 0.480 & 0.920 & 0.795 \\
\hline
\end{tabular}

\section{Conclusion}

In the virtual surgery system, the quality of the soft tissue model for surgical training is crucial. This paper proposes an optimized model for the local compression deformation of soft tissue. It refers to the finite element model as the reference model and optimizes the spring stiffness coefficient and damping coefficient by simulated annealing algorithm. Meanwhile, we adopt minimum vertical stress to calculate the vertical depth of the load center point under the intimal contact surface. We use vertical depth as the radius to divide the soft tissue into local deformation region and non-deformation region. Since only the points in the local deformation region are calculated, the calculation cost can be effectively reduced. In addition, we also set a compensation strategy for the over-compressed case to prevent the model from being "superelastic" due to excessive local pressure for ensuring the validity of the model.

In order to verify the reliability of our proposed model, we perform a compression simulation experiment of abdominal and human foot. We also compare the force-displacement curve and the time overhead for the deformation of our proposed model and other models. Moreover, we conduct a comparison of experimental training. The experimental results show that the deformation effect of our proposed model is realistic, with high authenticity and real-time performance, which can provide strong support for virtual surgery training.

\section{References}

[1] W. Wang and T. Zhang, "Integration of traditional Chinese medicine and Western medicine in the era of precision medicine,” Journal of integrative medicine, vol. 15, no. 1, pp. 1-7, 2017. Article (CrossRef Link)

[2] Z. Zhao, C. Xiu, J. Li and R. Li, "Study on the treatment of pelvic organ prolapse with combination of traditional Chinese and western medicine," in Proc. of 9th International Conference on Information Technology in Medicine and Education (ITME), pp.1047-1049, 2018. Article (CrossRef Link) 
[3] C. Ling, J. Fan, H. Lin, F. Shen, Z. Xu, L. Lin, S. Qin, W. Zhou, X. Zhai, B. Li and Q. Zhou, "Clinical practice guidelines for the treatment of primary liver cancer with integrative traditional Chinese and Western medicine,” Journal of integrative medicine, vol. 16, no. 4, pp. 236-248, 2018. Article (CrossRef Link)

[4] J. Zhang, M. Wu, Y. Wang, Y. Jia and E. Li, "Medicine in future and advantages of integrated Chinese and Western medicine," Chinese journal of integrative medicine, vol. 25, no. 2, pp. 87-90, 2019. Article (CrossRef Link)

[5] B. Jin, W. Yang, D. Sun and H. Li, "Current situation and reconsideration on the study of integrated chinese and western medicine andrology," Chinese journal of integrative medicine, pp.1-5, 2019. Article (CrossRef Link)

[6] J. Konstantinova, M. Li, G. Mehra, P. Dasgupta, K. Althoefer and T. Nanayakkara, "Behavioral characteristics of manual palpation to localize hard nodules in soft tissues," IEEE Transactions on Biomedical Engineering, vol. 61, no. 6, pp. 1651-1659, 2014. Article (CrossRef Link)

[7] S. Fang, Z. Cai, W. Sun, A. Liu, F. Liu, Z. Liang and G. Wang, "Feature selection method based on class discriminative degree for intelligent medical diagnosis," Computers, Materials \& Continua, vol. 55, no. 3, pp. 419-433, 2018. Article (CrossRef Link)

[8] P. Rohan, C. Lobos, M. Nazari, P. Perrier and Y. Payan, "Finite element models of the human tongue: a mixed-element mesh approach,” Computer Methods in Biomechanics and Biomedical Engineering: Imaging \& Visualization, vol. 5, no. 6, pp. 390-400, 2017. Article (CrossRef Link)

[9] P. Knoops, A. Borghi, F. Ruggiero, G. Badiali, A. Bianchi, C. Marchetti, N. Rodriguez-Florez, R. Breakey, O. Jeelani, D. Dunaway and S. Schievano, "A novel soft tissue prediction methodology for orthognathic surgery based on probabilistic finite element modelling,” PloS one, vol. 13, no. 5, pp. e0197209, 2018. Article (CrossRef Link)

[10] L. Vanegas-Useche, M. Abdel-Wahab and G. Parker, "Determination of the normal contact stiffness and integration time step for the finite element modeling of bristle-surface interaction," Computers, Materials \& Continua, vol. 56, no. 1, pp. 169-184, 2018. Article (CrossRef Link)

[11] I. Ahmad, "Local meshless method for PDEs arising from models of wound healing," Applied Mathematical Modelling, vol. 48, pp. 688-710, 2017. Article (CrossRef Link)

[12] Q. Cheng, P. Liu, P. Lai and Y. Wang, "An interactive meshless cutting model for nonlinear viscoelastic soft tissue in surgical simulators,” IEEE Access, vol. 5, pp. 16359-16371, 2017. Article (CrossRef Link)

[13] N. Omar, Y. Zhong, J. Smith and C. Gu, "Local deformation for soft tissue simulation," Bioengineered, vol. 7, no. 5, pp. 291-297, 2016. Article (CrossRef Link)

[14] Y. Duan, W. Huang, H. Chang, W. Chen, J. Zhou, S. Teo, Y. Su, C. Chui and S. Chang, "Volume preserved mass-spring model with novel constraints for soft tissue deformation," IEEE journal of biomedical and health informatics, vol. 20, no. 1, pp. 268-280, 2016. Article (CrossRef Link)

[15] S. Kshrisagar, A. Francis, J. Yee, S. Natarajan and C.K. Lee, "Implementing the node based smoothed finite element method as user element in abaqus for linear and nonlinear elasticity," Computers, Materials \& Continua, vol. 61, no. 2, pp. 481-502, 2019. Article (CrossRef Link)

[16] S. Behdadfar, L. Navarro, J. Sundnes, M. Malecker, S. Ross, H. Odland and S. Avril, "A centerline-based model morphing algorithm for patient-specific finite element modeling of the left ventricle,” IEEE Transactions on Biomedical Engineering, vol. 65, no. 6, pp. 1391-1398, 2018. Article (CrossRef Link)

[17] M. Wei, Y. Liu, H. Dong and A. Saddik, "Human head stiffness rendering," IEEE Transactions on Instrumentation and Measurement, vol. 66, no. 8, pp. 2083 - 2096, 2017. Article (CrossRef Link)

[18] G. Samei, O. Goksel, J. Lobo, O. Mohareri, P. Black, R. Rohling and S. Salcudean, "Real-time FEM-based registration of 3-D to 2.5-D transrectal ultrasound images," IEEE transactions on medical imaging, vol. 37, no. 8, pp. 1877-1886, 2018. Article (CrossRef Link)

[19] W. Traa, M. van Turnhout, K. Moerman, J. Nelissen, A. Nederveen, G. Strijkers, D. Bader and C. Oomens, "MRI based 3D finite element modelling to investigate deep tissue injury," Computer methods in biomechanics and biomedical engineering, vol. 21, no. 14, pp. 760-769, 2018.

Article (CrossRef Link) 
[20] M. Peyroteo, J. Belinha, S. Vinga, L. Dinis and R. Jorge, "Mechanical bone remodelling: Comparative study of distinct numerical approaches," Engineering Analysis with Boundary Elements, vol. 100, pp. 125-139, 2019. Article (CrossRef Link)

[21] Y. An, J. Liu, G. Zhang, S. Jiang, J. Ye, C. Chi and J. Tian, "Compactly supported radial basis function-based meshless method for photon propagation model of fluorescence molecular tomography," IEEE transactions on medical imaging, vol. 36, no. 2, pp. 366-373, 2017. Article (CrossRef Link)

[22] J. Zhou, Z. Luo, C. Li and M. Deng, "Real-time deformation of human soft tissues: A radial basis meshless 3D model based on Marquardt's algorithm," Computer methods and programs in biomedicine, vol. 153, pp. 237-252, 2018. Article (CrossRef Link)

[23] J. Hu, Y. Feng, S. Zhou, L. Huang, Q. Zeng, Y. Wu and Y. Li, "An improved mass spring model based on internal point set domain constraint," in Proc. of 29th Chinese Control and Decision Conference (CCDC), pp.6826-6831, 2017. Article (CrossRef Link)

[24] X. Zhang, P. Wang, W. Sun and N. Badler, "A novel twist deformation model of soft tissue in surgery simulation,” Computers, Materials \& Continua, vol. 55, no. 2, pp. 297-319, 2018. Article (CrossRef Link)

[25] X. Zhang, J. Duan, L. Zhu and L. Kavan, "A virtual puncture surgery system based on multi-layer soft tissue and force mesh,” Computers, Materials \& Continua, vol. 57, no. 3, pp. 505-519, 2018. Article (CrossRef Link)

[26] J. Tang, L. Xu, L. He, S. Guan, X. Ming and Q. Liu, "Virtual laparoscopic training system based on VCH model,” Journal of medical systems, vol. 41, no. 4, pp. 58, 2017. Article (CrossRef Link)

[27] C. Li, J. Ding, Z. Hong, Y. Pan and P. Liu, "A surface mass-spring model with new flexion springs and collision detection algorithms based on volume structure for real-time soft-tissue deformation interaction," IEEE Access, vol. 6, pp. 75572-75597, 2018. Article (CrossRef Link)

[28] W. Wang, L. Wang and F. Zheng, "An improved adaptive scheduling strategy utilizing simulated annealing genetic algorithm for data center networks," KSII Transactions on Internet and Information Systems, vol. 11, no. 11, pp. 5243-5263, 2017. Article (CrossRef Link)

[29] X. Han, Y. Dong, L. Yue and Q. Xu, "State transition simulated annealing algorithm for discrete-continuous optimization problems,” IEEE Access, vol. 7, pp. 44391-44403, 2019. Article (CrossRef Link)

[30] M. Yang, L. Ba, Y. Liu, H. Zheng, J. Yan, X. Gao and J. Xiao, "An improved genetic simulated annealing algorithm for stochastic two-sided assembly line balancing problem," International journal of simulation modeling, vol. 18, no. 1, pp. 175-186, 2019. Article (CrossRef Link)

[31] W. Duan, H. Zhang and C. Wang, "Deformation estimation for time series InSAR using simulated annealing algorithm,” Sensors, vol. 19, no. 1, pp. 115, 2019. Article (CrossRef Link)

[32] M. Frost, P. Sedlák, L. Heller, L. Kadeř́vek and P. Šittner, "Experimental and computational study on phase transformations in superelastic NiTi snake-like spring," Smart Materials and Structures, vol. 27, no. 9, pp. 095005, 2018. Article (CrossRef Link)

[33] B. Huang, Y. Lao, J. Chen and Y. Song, "Dynamic response analysis of a frame structure with superelastic nitinol SMA helical spring braces for vibration reduction," Journal of Aerospace Engineering, vol. 31, no. 6, pp. 04018096, 2018. Article (CrossRef Link)

[34] Z. Zhang, Z. Wu, Q. Jiang, L. Du and L. Hu, " Co-saliency detection based on superpixel matching and cellular automata," KSII Transactions on Internet and Information Systems, vol. 11, no. 5, pp. 2576-2589, 2017. Article (CrossRef Link)

[35] D. Karimi and S. Salcudean, " Reducing the Hausdorff distance in medical image segmentation with convolutional neural networks," IEEE Transactions on medical imaging, vol. 39, no. 2, pp. 499-513, 2019. Article (CrossRef Link)

[36] Y. Kang, S. Yoon, M. Kyung and M. Kim, "Fast and robust computation of the Hausdorff distance between triangle mesh and quad mesh for near-zero cases," Fuzzy Sets and Systems, vol. 378, pp. 144-156, 2020. Article (CrossRef Link)

[37] J. Rachasingho and S. Tasena, "A metric space of subcopulas-An approach via Hausdorff distance," Computers \& Graphics, vol. 81, pp. 61-72, 2019. Article (CrossRef Link) 
[38] W. Chen, K. Wong and Y. Chang, "The modified maximum shear stress failure theory of ductile material,” Applied Mechanics and Materials, vol. 727, pp. 99-102, 2015. Article (CrossRef Link)

[39] J. Jung, C. Kobayashi and Y. Sugita, " Kinetic energy definition in velocity Verlet integration for accurate pressure evaluation," The Journal of chemical physics, vol. 148, no. 16, pp. 164109, 2018. Article (CrossRef Link)

[40] Y. Zou, P. Liu, Q. Cheng, P. Lai and C. Li, “A new deformation model of biological tissue for surgery simulation,” IEEE transactions on cybernetics, vol. 47, no. 11, pp. 3494-3503, 2017. Article (CrossRef Link)

[41] M. Kot and H. Nagahashi, "Mass spring models with adjustable Poisson's ratio," The Visual Computer, vol. 33, no. 3, pp. 283-291, 2017. Article (CrossRef Link)

[42] W. Ye, A. Bel-Brunon, S. Catheline, A. Combescure and M. Rochette, "Simulation of nonlinear transient elastography: finite element model for the propagation of shear waves in homogeneous soft tissues," International journal for numerical methods in biomedical engineering, vol. 34, no. 1, pp. e2901, 2018. Article (CrossRef Link)

[43] C. Shen, L. Ren, J. Zhao, X. Tan and L. Wu, “A comprehensive evaluation index for shale reservoirs and its application: A case study of the Ordovician Wufeng Formation to Silurian Longmaxi Formation in southeastern margin of Sichuan Basin, SW China," Petroleum Exploration and Development, vol. 44, no. 4, pp. 686-695, 2017. Article (CrossRef Link)

[44] W. Fan, X. Xiao and S. Tao, "A multi-index evaluation method of voltage sag based on the comprehensive weight," in Proc. of 2018 China International Conference on Electricity Distribution (CICED), pp.613-617, 2018. Article (CrossRef Link)

[45] J. Xu, Y. Sun, Q. Sun and J. Ma, “A comprehensive evaluation index system of virtual power plant participating in power coordination and optimal dispatching," in Proc. of 2018 IEEE International Conference on Applied Superconductivity and Electromagnetic Devices (ASEMD), pp.1-2, 2018. Article (CrossRef Link) 


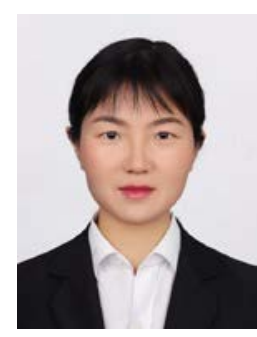

Xiaorui Zhang was born in 1979. She received her Ph.D. degree in Instrument Science and Technology Department of Southeast University, Nanjing, China, in 2010. She also received her B. S. and M. S. degrees from Henan University of Science and Technology, Henan, China, in 2004 and 2007, respective1y. Now she is a Professor in School of Computer and Software, Nanjing University of Information Science \& Technology. Her research interests include the virtual reality, human-computer interaction, and image processing.

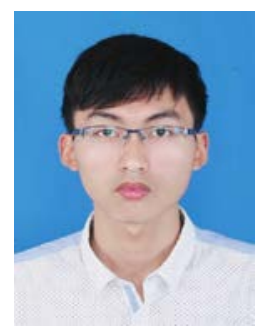

Xuefeng Yu was born in 1994. He received his B.S. degree in software engineering from Hefei Normal University, Hefei, China, in 2017. Now he is a master student in School of Computer and Software, Nanjing University of Information Science \& Technology. His main research interests include the virtual reality and human-computer interaction technology.

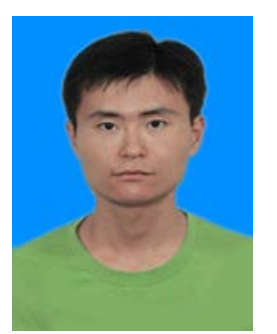

Wei Sun was born in 1980. He received his Ph.D. degree in Instrument Science and Technology Department of Southeast University, Nanjing, China, in 2010. He also received his B.S. and M.S. degrees from Henan University of Science and Technology, Henan, China, in 2004 and 2007, respectively. He is an Associate Professor in School of Automation, Nanjing University of Information Science \& Technology. His research interests include the machine vision, and the automobile active safety detection technology.

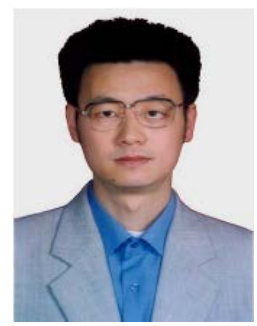

Aiguo Song was born in 1968. He received the Ph.D. degree in measurement and control from Southeast University, Nanjing, China, in 1996. He also received the B.S. degree in automatic control and the M.S. degree in measurement and control from Nanjing University of Aeronautics and Astronautics, Nanjing, China, in 1990 and 1993, respectively. He is currently a Professor in School of Instrument Science and Engineering, Southeast University. His current interests concentrate on teleoperation, haptic display, Internet telerobotic, and distributed measurement systems. 